Sergio Fragoso, Mario L. Ruz, Juan Garrido, Francisco Vázquez, Fernando Morilla, Educational software tool for decoupling control in wind turbines applied to a lab-scale system, Computer Applications in Engineering Education, vol. 24, issue 3, pp. 400-411, 2016. ISSN: 1099-0542. The Version of Record of this manuscript has been published and is available at https://onlinelibrary.wiley.com/doi/full/10.1002/cae.21718 (https://doi.org/10.1002/cae.21718)

\title{
Educational software tool for decoupling control in wind turbines applied to a
}

\author{
lab-scale system
}

\author{
S. Fragoso, M. L. Ruz, J. Garrido, F. Vázquez, F. Morilla
}

\begin{abstract}
This paper presents an educational software tool, called wtControlGUI, whose main purpose is to show the applicability and performance of different decoupling control strategies in wind turbines. Nowadays wind turbines are a very important field in control engineering. Therefore, from an educational point of view, the tool also aims to improve the learning of multivariable control concepts applied on this control field. In addition, wtControlGUI allows for testing and control of a lab-scale system which emulates the dynamic response of a largescale wind turbine. The designed graphical user interface essentially allows simulation and experimental testing of decoupling networks and other multivariable methodologies, such as robust and decentralized control strategies. The tool is available for master degree students in control engineering. A survey was performed to evaluate the effectiveness of the proposed tool when used in educational related tasks.
\end{abstract}

Keywords: Educational software tool; multivariable control; decoupling control; wind turbines

\section{INTRODUCTION}

Multiple-Input-Multiple-Output (MIMO) processes are common in industry. Wind turbines can be considered multivariable processes. There are several control strategies for these kinds of processes and several options to tune the controllers that are part of such strategies. Thus, analysis of MIMO processes is considered to be of fundamental interest for control engineers, and MIMO control strategies have been 
and are still, widely investigated. In general, MIMO control systems can be classified into centralized and decentralized control systems. Centralized control techniques are used when the interaction level between the process variables is so high that the problem cannot be solved with decentralized control techniques. Multivariable control methodologies with decoupling networks presented in this work, called decoupling control, are involved in the category of centralized control techniques.

Wind turbines can work in several operational modes depending on the wind speed: cut-in (I), partial load (II), transition (III), full load (IV) and cut-out (V). Figure 1 illustrates these regions. This figure shows the ideal power curve of a wind turbine.

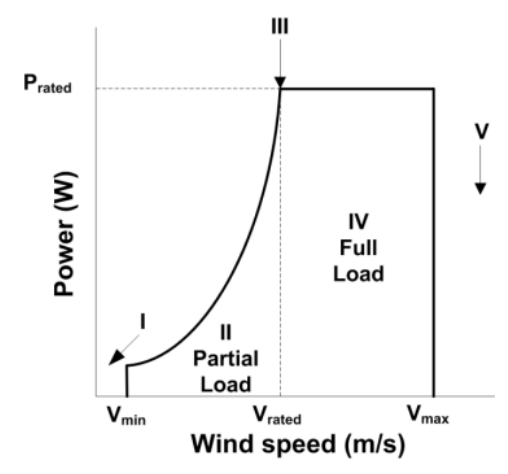

Figure 1 Wind turbine operation modes

Many multivariable control methodologies have been implemented in wind turbines, from traditional decentralized Proportional-Integral-Derivative (PID) controllers [1] to more advanced techniques, such as fuzzy logic controllers [2], neural network-based controls [3], model predictive controls [4], robust $H_{\infty}$ controls [5], optimal Linear Quadratic Gaussian (LQG) controls [6], and Linear Parameter Varying (LPV) controls [7], which indicates the interest that has been and continues in this field.

Traditionally, these kinds of processes have been controlled using single-loop PID controllers [8]. This approach is suitable when the interaction is moderate [9]. Nevertheless, when the interaction level is more significant, the system performance can be deteriorated. These interactions are particularly greater in the transition mode (III), between partial load (II) and full load (IV). Therefore, in these cases, more complex multivariable control strategies such as multivariable centralized control can be advisable to reduce the 
interactivity between variables [10]. It is important to note that controllers with decoupling networks try to achieve a good performance not only in the transition mode but also in all operational modes.

Large-scale wind energy has become an established technology within the social concerns to find an increase in clean and sustainable energy. In many countries, different regulations have been established to implant this technology [11]. These regulations, as well as its modifications condition the wind turbines and wind farms design and implantation. The wind energy industry promotes the demand of qualified electronic, electrical and control engineers who can understand and cope with the difficulties inherent in the wide range of disciplines and the different scenarios involved [12]. From an educational point of view, the traditional lectures and customary laboratory teaching do not seem to be an optimal approach for such a dynamic and complex field.

Modelling and dynamic simulation are now considered basic tools to strengthen the theoretical aspects in the engineering teaching [13]. Nevertheless, in situ experimentation with a real plant cannot be replaced by simulations, and the practical teaching needs to be based on real aspects which occur in industrial systems. Experience has shown that students are more motived to learn new concepts if they are faced with real-life industrial applications [14].

In this aspect, the main objective of this paper is to propose an educational software tool developed in the Matlab/Simulink environment [15] to support the learning of theoretical concepts of decoupling control. At the same time, the users are confronted to design and check a multivariable control system which regulates a lab-scale wind turbine. This lab-scale system emulates a large-scale one, essentially in the mechanical component.

\section{LAB-SCALE SYSTEM DESCRIPTION}

The wtControlGUI educational software tool can be connected with a lab-scale variable-speed variablepitch (VS-VP) wind turbine. This wind turbine emulates faithfully the dynamic response of a large-scale one. The lab-scale wind turbine includes a rotor with two blades and direct coupling without gearbox to a permanent magnet DC electric generator (Figure 2). This feature supposes a technology simplification of 
the process respect to large-scale wind turbines, which facilities the learning and study of the electrical component of the system.

The rotor and the electric generator are placed in a small wind tunnel which incorporates four platens to channel the wind flow to the blades. The wind speed profile is emulated with a three-phase fan. The wind flow coming from the fan crosses a grille to convert the turbulent flow in laminar flow. The main technical parameters of the equipment are listed in Table 1.

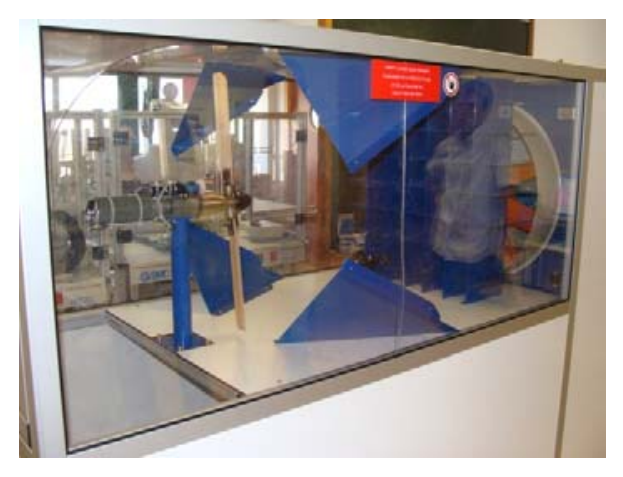

Figure 2 Lab-scale wind turbine details

The lab-scale wind turbine is controlled by a computer which acts as the main controller. The controller works in Matlab/Simulink environment, using the Real-Time Windows Target toolbox. The Real-Time Workshop (RTW) is an automatic C language code generator for Simulink. It produces C code directly from the Simulink block diagram models and automatically builds programs that can be run in real time in a variety of environments, including real-time hardware such as microcontrollers or digital signal processors (DSP) [16].

Table 1 Technical parameters of the lab-scale wind turbine.

\begin{tabular}{lc}
\hline Parameter & Value \\
\hline Rotor radius $(R)$ & $297.5 \mathrm{~mm}$ \\
Rated power $\left(P_{g r}\right)$ & $80 \mathrm{~W}$ \\
Rated speed $\left(\omega_{r r}\right)$ & $1810 \mathrm{rpm}$ \\
Rated voltage $\left(U_{g r}\right)$ & $24 \mathrm{~V}$ \\
Rated current $\left(I_{g r}\right)$ & $2.94 \mathrm{~A}$ \\
Rotor inertia $\left({ }_{r}\right)$ & $11000 \mathrm{gcm}^{2}$ \\
Generator inertia $\left(J_{g}\right)$ & $1340 \mathrm{gcm}^{2}$ \\
Generator armature & $1.44 \Omega$ \\
resistance $\left(R_{a}\right)$ & \\
Generator armature & $0.56 \mathrm{mH}$ \\
inductance $\left(L_{a}\right)$ & \\
\hline
\end{tabular}




\begin{tabular}{lc}
\hline Speed constant $\left(k_{b}\right)$ & $95.3 \mathrm{rpm} / \mathrm{V}$ \\
Torque constant $\left(k_{t}\right)$ & $100 \mathrm{mNm} / \mathrm{A}$ \\
Efficiency $(\eta)$ & $77 \%$ \\
Load resistance $\left(R_{L}\right)$ & $22 \Omega(100 \mathrm{~W})$ \\
\hline
\end{tabular}

\section{WIND TURBINE MODELLING}

This section is devoted to present briefly the general physical modelling which describes the behaviour of a wind turbine. At the same time, the mathematical relation between the variables which act as control and process variables is shown. A detailed explanation and description of wind turbine systems can be consulted in [17], [18], [19].

Roughly speaking, the general structure of a wind turbine is composed of a mechanical subsystem and an electrical subsystem [20]. The first one consists of a turbine rotor, which includes the aerodynamic components, a gearbox (if any) and the low-speed and high-speed axes. The electrical subsystem consists of a generator unit, which can be split in the electric generator and the static converter. The static converter is connected to a load or grid. Next paragraphs summarize the physical description of these two subsystems, specifically considering the lab-scale wind turbine used in this work.

\section{Mechanical subsystem description}

Assuming a rigid speed shaft and direct coupling between the rotor and the electric generator, a one-mass model can be used to describe the dynamic of this subsystem [21].

$$
J_{t} \frac{d \omega_{r}}{d t}=\tau_{a}-\tau_{e m}
$$

where $\omega_{r}$ is the rotor speed, $\tau_{e m}$ is the electromagnetic torque of the generator and $\tau_{a}$ is the aerodynamic torque. $J_{t}$ is the total inertia moment. The aerodynamic torque is generated by the wind forces and it 
depends on the aerodynamic properties of the turbine [22]. The torque $\tau_{a}$ is given by the nonlinear expression,

$$
\tau_{a}=\frac{1}{2} \rho \pi R^{3} \frac{C_{p}(\lambda, \beta)}{\lambda} v^{2}
$$

where $R$ is the radius of the rotor, $v$ is the wind speed, and $\lambda$ is the tip-speed ratio (TIP), which is defined as the ratio between the linear blade tip speed and the wind speed.

$$
\lambda=\frac{\omega_{r} R}{v}
$$

The power coefficient, $C_{p}(\lambda, \beta)$, depends on the tip-speed ratio and the blade pitch angle $\beta$, is the most important parameter for the design of the wind turbines control systems, especially in the power regulation case [23]. This coefficient considerably contributes to the non-linear nature of the system. In practice, it is difficult to obtain and is different for every wind turbine. In this study, a polynomial fitting was carried out from experimental data. By extrapolation techniques, it has been possible to obtain a three-dimensional representation of this power coefficient as a function of the tip-speed ratio and the pitch angle. Figure 3 shows the corresponding surface for the experimental power coefficient of the lab-scale wind turbine. As it is shown in Figure 4, the optimal point is achieved at a tip-speed ratio of 6.8 and pitch angle of $1^{\circ}$.

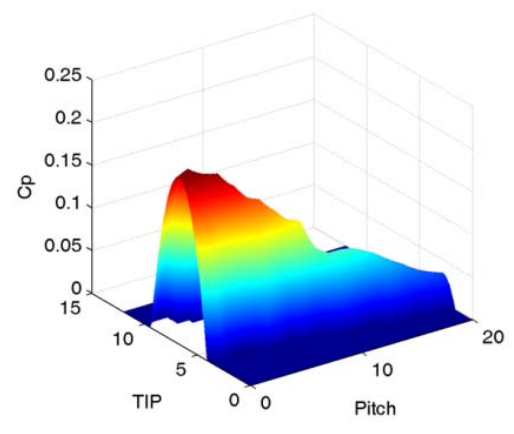

Figure 3 Experimental power coefficient $C_{p}(\lambda, \beta)$ surface 


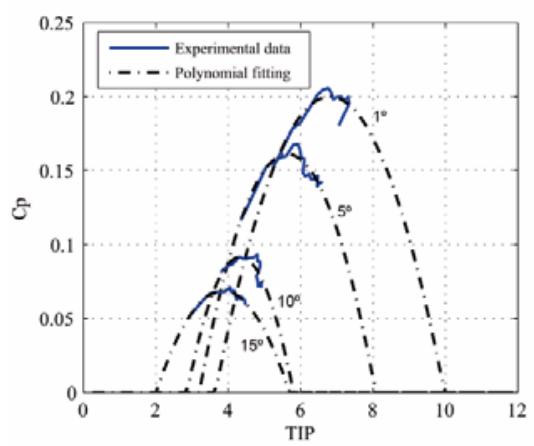

Figure $4 C_{p}$ polynomial fitting

\section{Electrical subsystem description}

As mentioned before, the lab-scale wind turbine used in this study has a permanent-magnet DC electric generator. The electromagnetic torque $\tau_{e m}$ can be modified by controlling the armature current $i_{g}$ according to (4). Therefore, a change in the generated torque conditions causes a change in the electric power conditions, as indicated by equation (5). The parameters $\eta$ and $k_{t}$ represent the efficiency and the torque constants of the electric generator, respectively.

$$
\begin{gathered}
\tau_{e m}=k_{t} i_{g} \\
P_{g}=\eta \tau_{e m} \omega_{r}
\end{gathered}
$$

The armature current flows across the load. Modifying this current causes changes in the generated torque and the electric power. This requires having a variable load [24]. In this case, a variable load resistance was implemented by using the pulse-width-modulation (PWM) technique. Using a $2 \mathrm{KHz}$ PWM signal generated by a microcontroller, the apparent resistance can be modified as a function of the duty cycle $\alpha$ between the nominal resistance $(100 \%$ duty cycle) and open circuit (at $0 \%$ duty cycle). Hence, increasing the duty cycle decreases the resistance, producing a larger current $i_{g}$ to flow through the generator, which increases the generator torque.

\section{DECOUPLING CONTROL}

This section describes the multivariable control structures with decoupling networks implemented in the 
tool. The decoupling control techniques proposed in this tool are based on linear systems. Thus, linear plant models were identified in different operating points. The identification process and the transfer function matrices of the linear models can be consulted in [25]. The linear models are defined according to $(6)$, where $G(s)$ is the process transfer matrix, and $G_{D}(s)$ is the disturbance matrix associated with the wind speed input.

$$
\left(\begin{array}{c}
\omega_{r} \\
P_{g}
\end{array}\right)=G(s)\left(\begin{array}{c}
\beta \\
\alpha
\end{array}\right)+G_{D}(s) v
$$

The process inputs are the blade pitch angle, $\beta$, and the duty cycle, $\alpha$. In the lab-scale wind turbine, the pitch angle ranges from $0^{\circ}$ to $25^{\circ}$ and the duty cycle from $0 \%$ to $100 \%$. The process outputs are the rotor angular speed, $\omega_{\mathrm{r}}$, and the generated electric power, $\mathrm{P}_{\mathrm{g}}$. From a control point of view, the wind speed, $v$, represents a disturbance input for the process.

A centralized control system with a decoupling network can be designed by combining a diagonal controller, $C(s)$, with a decoupling network, $D(s)$, such that the diagonal controller sees the apparent process $Q(s)=G(s) \cdot D(s)$ as a set of $\mathrm{n}$ completely independent processes.

A decoupling scheme can be static or dynamic. Although there are many decoupling methods, most of them use a conventional decoupling scheme in which the process inputs are derived by a time-weighted combination of feedback controller outputs. Figure 5a shows the $2 \times 2$ conventional decoupling scheme where $y_{1}$ and $y_{2}$ are the process outputs, $u_{1}$ and $u_{2}$ are the process inputs, and $r_{1}$ and $r_{2}$ the reference signals. In the inverted decoupling scheme (Figure $5 \mathrm{~b}$ ), the process inputs are fed back to the decoupling network inputs through decoupling elements to be combined with the controller outputs. Depending on the decoupling network, different apparent processes $Q(s)$ can be obtained. 


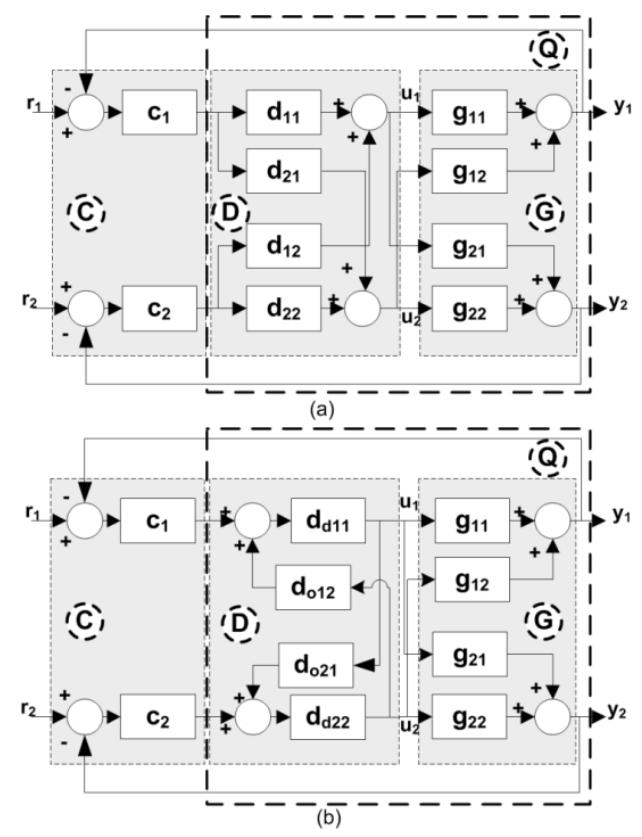

Figure 5 Decoupling control system of a $2 \times 2$ process: (a) conventional decoupling; (b) inverted decoupling

In the tool, the following three decoupling schemes were implemented:

- Dynamic simplified decoupling

- $\quad$ Static simplified decoupling

- Inverted decoupling

These decoupling schemes are explained in the following.

\section{Dynamic simplified decoupling}

In dynamic simplified decoupling, $n$ elements of the decoupler, generally the diagonal ones, are set to unity. For a $2 \times 2$ system, the general expressions of the decoupler, $D(s)$, and the diagonal apparent process, $Q(s)$, are cited in [26] and showed in (7)-(8).

$$
D(s)=\left(\begin{array}{cc}
1 & \frac{-g_{12}(s)}{g_{11}(s)} \\
\frac{-g_{21}(s)}{g_{22}(s)} & 1
\end{array}\right)
$$




$$
Q(s)=\left(\begin{array}{cc}
g_{11}(s)-\frac{g_{12}(s) g_{21}(s)}{g_{22}(s)} & 0 \\
0 & g_{22}(s)-\frac{g_{12}(s) g_{21}(s)}{g_{11}(s)}
\end{array}\right)
$$

\section{Static simplified decoupling}

Static simplified decoupling is a version of simplified decoupling that only decouples the process at the stationary state. The decoupler is only calculated with the information of the steady state gain of the process according to (9). It is observed in (10) that non-perfect decoupling is obtained because the offdiagonal elements of $Q(s)$ are non-zero.

$$
\begin{gathered}
D(s)=\left(\begin{array}{cc}
1 & \frac{-g_{12}(0)}{g_{11}(0)} \\
\frac{-g_{21}(0)}{g_{22}(0)} & 1
\end{array}\right) \\
Q(s)=\left(\begin{array}{ll}
g_{11}(s)-\frac{g_{21}(0) g_{12}(s)}{g_{22}(0)} & g_{12}(s)-\frac{g_{12}(0) g_{11}(s)}{g_{11}(0)} \\
g_{21}(s)-\frac{g_{21}(0) g_{22}(s)}{g_{22}(0)} & g_{22}(s)-\frac{g_{12}(0) g_{21}(s)}{g_{11}(0)}
\end{array}\right)
\end{gathered}
$$

\section{Inverted decoupling}

Using the structure of inverted decoupling (Figure 5b), it is possible to obtain an apparent process in $Q(s)$ that is as simple as the diagonal elements of $G(s)$, while the decoupler elements are the same as those of the dynamic simplified decoupling [13]. In inverted decoupling, the entire decoupler, $D(s)$, is divided into two matrices: a diagonal matrix, $D d(s)$, in the direct path and an off-diagonal matrix, $D o(s)$, in a feedback path. The expressions of the decoupler matrices and the corresponding apparent process appear in [26] and they are showed in (11) and (12).

$$
\begin{gathered}
D d(s)=\left(\begin{array}{ll}
d_{d 11} & d_{d 12} \\
d_{d 21} & d_{d 22}
\end{array}\right) \quad D o(s)=\left(\begin{array}{cc}
0 & \frac{-g_{12}(s)}{g_{11}(s)} \\
\frac{-g_{21}(s)}{g_{22}(s)} & 0
\end{array}\right) \\
Q(s)=\left(\begin{array}{cc}
g_{11}(s) & 0 \\
0 & g_{22}(s)
\end{array}\right)
\end{gathered}
$$

\section{OTHER CONTROL METHODOLOGIES}

WtControlGUI allows comparing the decoupling control strategies with other multivariable control methodologies. A decentralized control and $H_{\infty}$ robust control strategies were also implemented. In this 
section, these strategies are briefly described.

\section{Traditional decentralized PID control}

For pure decentralized control, the scheme depicted in Figure 6 is used. The process model is represented by the $g_{n \times n}(s)$ blocks. This control scheme uses PID controllers, represented with $c_{1}(s)$ and $c_{2}(s)$ blocks for each control loop. The wind speed disturbance is considered in the scheme with the $g_{13}(s)$ and $g_{23}(s)$ blocks.

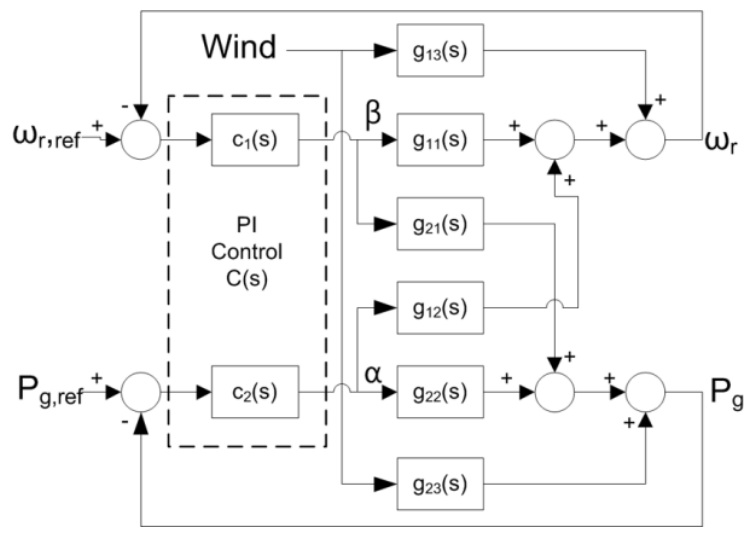

Figure 6 Decentralized PI control scheme

\section{Robust control}

The multivariable robust controller design problem can be formulated as an $H_{\infty}$ optimization problem through the so-called S/KS/T mixed sensitivity configuration [27]. This configuration is shown in Figure 7. $P(s)$ is the extended plant, where $G(s)$ represents the wind turbine model, $K(s)$ the controller, $u$ represents the set of control signals, $\omega$ the exogenous signals, $v$ the measured variables and $z$ the error variables.

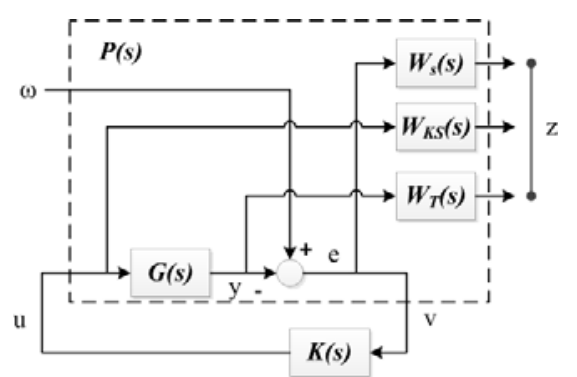


Figure $7 \mathrm{~S} / \mathrm{KS} / \mathrm{T}$ mixed sensitivity configuration

The matrices $W_{S}(s), W_{K S}(s)$ and $W_{T}(s)$ are the weighting matrices of the configuration, which allow specifying the range of relevant frequencies for the closed loop transfer matrix $T_{z w}(s)$.

$$
T_{z \omega}(s)=\left[\begin{array}{c}
W_{s}(s) S_{o}(s) \\
W_{K S}(s) K(s) S_{o}(s) \\
W_{T}(s) T_{o}(s)
\end{array}\right]
$$

The selection of these matrices has been accomplished following the design rules specified in [27]. $W_{s}(s)$ is a square diagonal matrix, where the diagonal elements are described by expression (14). In this expression, $\omega_{T}$ is the crossover frequency of the diagonal elements of $W_{T}(s), \alpha_{i}$ and $\beta_{i}$ are the gains at high and lows frequencies, respectively. The parameter $k_{i}$ adjusts the response speed of the outputs.

$$
w_{s i}(s)=\frac{\alpha_{i} s+10^{\left(k_{i}-1\right)} \omega_{T}}{s+\beta_{i} 10^{\left(k_{i}-1\right)} \omega_{T}}, \quad i=1,2
$$

$W_{T}(s)$ is a square diagonal matrix with all its diagonal elements with the same transfer function. $w_{\text {Tdiag }}(s)$ is a transfer function which must be stable, minimum phase, with high gain at high frequencies, and with magnitude greater than the maximum singular value of the uncertainty computed for each non-nominal model [28].

$$
W_{T}(s)=w_{\text {Tdiag }}(s) \cdot I
$$

The matrix $W_{s}(s)$ is obtained as square diagonal matrix of transfer functions

$$
W_{s}(s)=\left[\begin{array}{cc}
w_{s 1}(s) & 0 \\
0 & w_{s 2}(s)
\end{array}\right]
$$

For practical purposes, $\alpha_{i}, \beta_{i}$ and $k_{i}$ represent three tuning parameters to adjust the robust controller. The aforementioned expressions can be defined in wtControlGUI tool.

\section{TOOL DESCRIPTION}

This section is aimed to describe the main features of the interactive tool. The can be downloaded from http://www.uco.es/grupos/prinia/sergio-fragoso-herrera/, and the simulation mode can be tested. This tool is in harmony with other educational tools for the study of control engineering. For instance, in [29], [30] 
some similar interactive tools are referenced, which were developed with the collaboration of the University of Cordoba and National Distance Education University in Spain.

The main idea was not only to obtain a tool for analyzing the performance of multivariable decoupling control strategies, but also to develop a tool sufficiently educational. This tool must be useful for the assimilation of the basic concepts of decoupling control and the wind generation process.

The main window is depicted in Figure 9. It is divided in several differentiated parts (a-g). The work flow with the tool is divided in several stages and is described by Figure 8 .

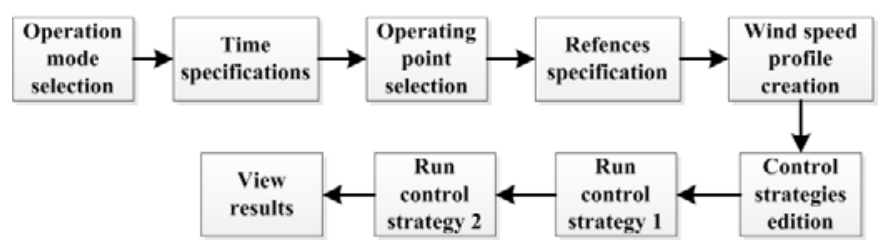

Figure 8 Work flow description of the tool

1. Operation mode selection (a). The tool allows comparing two control strategies at same time. This comparison can be done in three modes: simulation vs simulation, simulation vs experimental and experimental vs experimental. In the simulation mode, the control strategies are simulated with the identified linear model in the selected operating point. In the experimental mode, the tool is connected with the lab-scale wind turbine and operates it setting the selected operating point.

If the Save data check box is selected, the tool saves the last data result in a Matlab mat-file. The name of this file can be introduced in the File name text box. This option allows an off-line analysis of the results.

2. Time specifications for the simulation and experimental test (b). It is necessary previously to set the duration in seconds of the simulation and experimental tests.

3. Operating point selection (c). As mentioned before, the lab-scale wind turbine has been identified in five operating points, which are represented in different regions of Fig. 1. In particular, there are two points in the partial load region, at wind speeds of $6 \mathrm{~m} / \mathrm{s}$ and $7 \mathrm{~m} / \mathrm{s}$; one point in the transition region at $8 \mathrm{~m} / \mathrm{s}$; and finally, two points in the full load region, at $9 \mathrm{~m} / \mathrm{s}$ and $10 \mathrm{~m} / \mathrm{s}$. In the main window, the ideal curve graph appears and the user can observe the location of each operating point. 
By clicking on the Process scheme button, the user can observe the general block scheme of the process and identify the inputs and outputs of the system, the blocks that form the wind turbine model and the wind disturbance model. By clicking on the Transfer function matrix info. button, it is possible to observe numerically the transfer function matrices in accordance with the process block scheme for the selected operating point. Together with these matrices, the Relative Gain Array (RGA) is also displayed. The RGA allows quantifying numerically the interaction level between input and output variables.

4. Step change specification (d). One objective of wtControlGUI is to verify the interaction effects between the wind turbine variables, as well as to show how decoupling control strategies can reduce these effects. The most simple and intuitive way to prove the interaction level between variables is to produce a step change in the set-point for the output variables. In this section, the user should specify the initial set-point for each output variable, the new set-point and the step change time. The new values for the set-points should not be greater than $\pm 15 \%$ with respect the initial value. With this restriction, problems with the range of validity of the linear models are avoided. The set-points are automatically adjusted when the operating point is selected.

5. Wind speed profile creation (e). The tool also allows reproducing a wind speed profile, which is based on [31]. If the Wind speed profile button is clicked, a new window appears to select and configure the wind speed components (Figure 10). The available wind speed profile components are: mean component, turbulence, gust, ramp and sinusoidal component. The components are individually selectable and configurable with the exception of the mean component. The mean component is automatically adjusted when the operating point is selected, and it cannot be changed. The turbulence component is characterized by a standard deviation value. The gust and ramp components are edited by three parameters: initial time, final time and amplitude. The sinusoidal component is composed by a frequency value and amplitude value. 


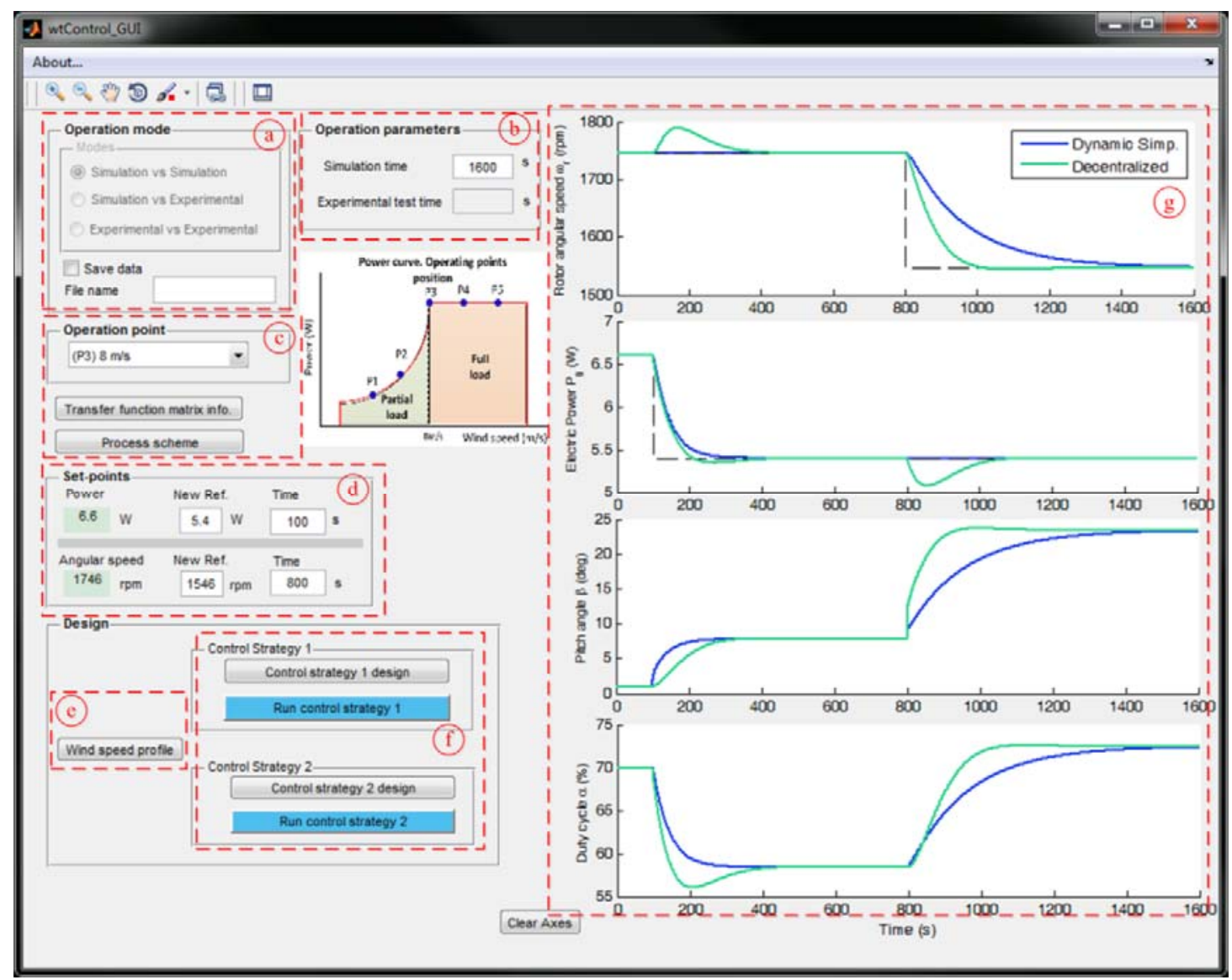

Figure 9 wtControlGUI main window

By clicking on the Plot wind speed profile button, the wind speed profile configured is plotted.

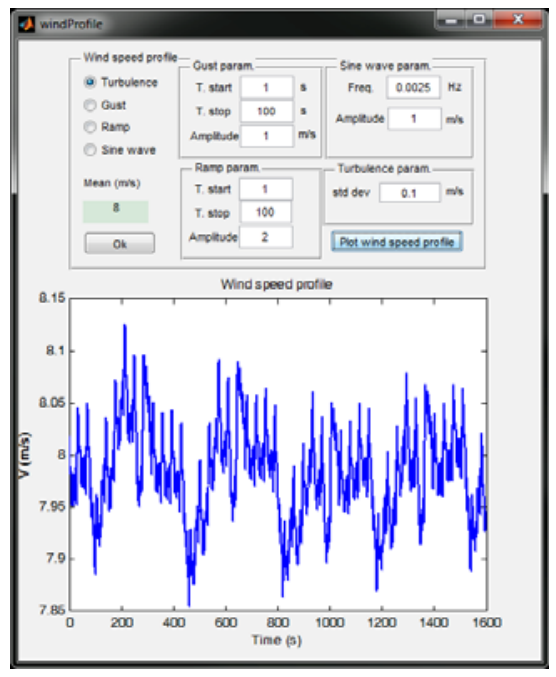

Figure 10 Wind speed profile edition window 
6. Control strategy selection (f). The tool allows choosing, configuring and comparing two control strategies. Thus, the user should configure and simulate or test the first control strategy and then proceed in the same way with the second control strategy. For this purpose, by clicking on the Control strategy 1 design or Control strategy 2 design button, a new window is shown. Figure 11 depicts this window. The reason of including two control strategy windows is due to the ease of comparing the dynamic responses when modifying the strategy and its control parameters.

When one of the decoupling control strategies is selected, the associated decoupling matrices can be shown by clicking on the Decoupling matrix info. button. In addition, the tool allows the user to observe the block scheme of each control strategy, by clicking on the Control strategy scheme button.

By clicking on the Load def. Param button, the default tuning parameters for the PI controllers are selected for a specific control strategy and operating point. At the same time, the user can save and recover the configured tuning parameters as user parameters, by simply clicking on the Save User Param. and Load User Param. buttons, respectively.

The section Robust control param is only enabled when the robust control strategy is selected. In this section the user can introduce the tuning parameters for each control loop, as well as the transfer functions $w_{\text {Tdiag }}(s), w_{s 1}(s)$ and $w_{s 2}(s)$.

In order to establish a quantitative comparative between different control strategies, Integral Absolute Error (IAE) and the Standard Deviation (StD) are calculated. 


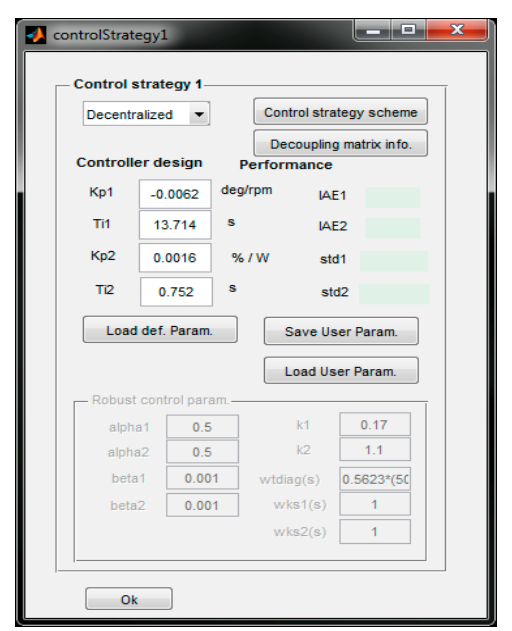

Figure 11 Control strategy edition window

7. Plotting results $(\mathbf{g})$. The tool shows the results in four graphs, two graphs for the output variables $\left(\omega_{r}\right.$ and $\left.P_{g}\right)$ and two graphs for the input variables $(\beta$ and $\alpha)$.

\section{Illustrative example}

There are different comparative scenarios that can be illustrated with wtControlGUI. The aim of this illustrative example is to show how the decoupling techniques can reduce the interaction effect between variables when the system is controlled and can improve its performance. This example shows the tool as a platform for obtaining simulation and experimental data.

Specifically, the dynamic simplified decoupling control and decentralized control have been compared in the transition region. This region is reached with a wind speed of $8 \mathrm{~m} / \mathrm{s}$ for the lab-scale wind turbine. In this region, the interaction between variables is greater, as shown in the RGA analysis in Table 2 . Considering this aspect, this operating point could be the most problematic point for the control strategies that do not take into account the coupling problem, such as decentralized control. 
Table 2 RGA in the operating points

\begin{tabular}{lc}
\hline Wind speed & $\lambda_{11}$ RGA \\
\hline $6 \mathrm{~m} / \mathrm{s}$ & 0.9151 \\
$7 \mathrm{~m} / \mathrm{s}$ & 0.7471 \\
$8 \mathrm{~m} / \mathrm{s}$ & 0.6543 \\
$9 \mathrm{~m} / \mathrm{s}$ & 0.7606 \\
$10 \mathrm{~m} / \mathrm{s}$ & 0.8118 \\
\hline
\end{tabular}

In (17) and (18) the matrices of the linear model in the transition region are presented, according to (6). These matrices are displayed if the Transfer function matrix info. button is clicked.

$$
\begin{gathered}
G(s)=\left(\begin{array}{cc}
\frac{-8.3951}{118.4 s^{2}+21.77 s+1} & \frac{-491.4}{35.36 s^{2}+11.89 s+1} \\
\frac{-0.06102}{16.93 s+1} & \frac{6.7614}{0.93526 s+1}
\end{array}\right) \\
G_{D}(s)=\left(\begin{array}{cc}
\frac{345}{104.6 s^{2}+20.45 s+1} \\
\frac{2.341}{41.53 s^{2}+14.85 s+1}
\end{array}\right)
\end{gathered}
$$

By expression (7), the decoupling matrix of the dynamic simplified decoupling is showed in (19). As mentioned before, this matrix can be observed by clicking on the Decoupling matrix info. button, located inside the control strategy design window.

$$
D(s)=\left(\begin{array}{cc}
1 & \frac{-196 s^{2}-36.04 s-1.655}{s^{2}+0.34 s+0.028} \\
\frac{0.00049 s+0.00053}{s+0.059} & 1
\end{array}\right)
$$

Control Strategy 1 simulates the dynamic simplified decoupling. The controllers use a ProportionalIntegral (PI) structure with the following values for the proportional gains: $k_{p 1}=-0.0062 \mathrm{deg} / \mathrm{rpm}$ and $k_{p 2}=0.0016 \% / W$, respectively and with the following integral times: $T_{i 1}=13.714 \mathrm{~s}$ and $T_{i 2}=$ $0.752 \mathrm{~s}$, respectively for each control loop.

Control Strategy 2 simulates the decentralized control. In this case, the following tuning parameters were selected: $k_{p 1}=-0.021 \mathrm{deg} / \mathrm{rpm}, k_{p 2}=0.0094 \% / W, T_{i 1}=18.301 \mathrm{~s}$ and $T_{i 2}=2.86 \mathrm{~s}$. 
In this operating point, the initial set-points are $1746 \mathrm{rpm}$ and $6.6 \mathrm{~W}$, respectively. At 100 seconds of simulation a step change of $-1 \mathrm{~W}$ in the set-point of the generated power is established. In the same way, at 800 seconds of simulation the set-point of the angular speed is modified and decreased in $200 \mathrm{rpm}$. Simulation results are shown in section $g$ of Figure 9. As can be seen from the plots, the dynamic simplified decoupling (blue line) reduces the disturbance effect with respect to the decentralized control strategy (green line) when a step change occurs.

If the Save data check box is selected, the last results are saved in a mat-file. This option allows processing off-line the results of several simulations and experimental tests and comparing more than two strategies simultaneously.

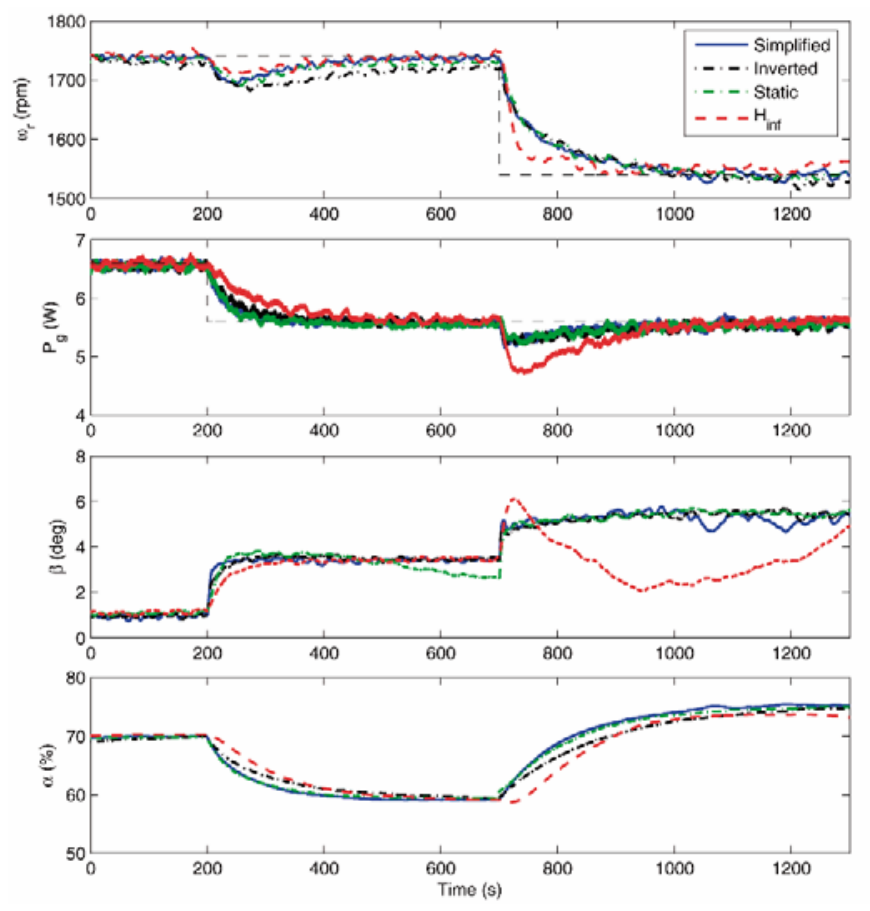

Figure 12 Experimental results

Figure 12 shows a comparative of experimental results of four control strategies (dynamic simplified decoupling, static simplified decoupling, inverted decoupling and robust control), where the transition region again was chosen as the operating point. In this particular case, there are set-point step changes similar to those of the simulation case. From a qualitative point of view, the results point out no methodology achieves perfect decoupling, especially the inverted decoupling due to modelling errors. 
Nevertheless, the performance achieved by the decoupling control strategies is slightly better than that obtained by the robust control. Table 3 summarizes the performance indices which confirm the quantitative improvement obtained for the decoupling techniques.

Table 3 Experimental performance indices

\begin{tabular}{|c|c|c|c|c|}
\hline & $\boldsymbol{I A E}_{\mathbf{1}}$ & $\boldsymbol{I A E}_{\mathbf{2}}$ & $\boldsymbol{S t d}_{\mathbf{1}}$ & $\boldsymbol{S t d}_{\mathbf{2}}$ \\
\hline$H_{\infty}$ & $1.878 \cdot 10^{4}$ & 243.88 & 88.82 & 0.474 \\
\hline $\begin{array}{c}\text { Dynamic } \\
\text { simplified } \\
\text { decoupling }\end{array}$ & $2.240 \cdot 10^{4}$ & 106.03 & 87.81 & 0.387 \\
\hline $\begin{array}{c}\text { Static } \\
\text { simplified } \\
\text { decoupling }\end{array}$ & $2.956 \cdot 10^{4}$ & 99.84 & 85.57 & 0.387 \\
\hline $\begin{array}{c}\text { Inverted } \\
\text { decoupling }\end{array}$ & $3.149 \cdot 10^{4}$ & 132.89 & 82.03 & 0.392 \\
\hline
\end{tabular}

\section{ASSESSMENT AND EVALUATION}

According to Balchen et a.l [32], a good laboratory experiment should include a pedagogical guidelines: to demonstrate important theoretical ideas, reflect important real-life problems, give a good visual sensation, have a suitable time scale, and be easy to understand and use. The educational tool together with the lab-scale wind turbine addresses these requirements in several ways.

- Theoretical ideas: With this tool, the students in a control engineering subject can strengthen basic concepts in process control such as: MIMO control structures, robust control, the design of PID controllers for the control of a MIMO system, modelling of a system (wind turbine). On the other hand, to learn new and more advanced control concepts, such as decoupling control methodologies.

- Real-life problem: Wind turbine control is a very important field for control engineers because nowadays the Wind Energy Conversion Systems (WECS) suppose a high percentage in the power generation to world level. In this sense, the tool allows interconnecting with a lab-scale system 
which emulates the main control difficulties of real wind turbine and the students are confronted with real problems.

- Visual sensation: The graphical user interface is structured coherently. The information displayed in the main window was reduced as much as possible to facilitate the navigation.

- Suitable time scale: The simulation tests are practically immediate whereas the experimental tests take approximately 40 minutes, less than a traditional practical session (2-h).

- Easy to understand and use: The graphical user interface has been designed to be user-friendly. However, the students are guided in using the tool by the teacher, who will explain in detail the state flow shown in Figure 8.

Enrolled students in the course of Control Engineering in the Automatic Control Engineering degree, at the University of Cordoba, were required to submit an electronic questionnaire to the teacher. Through practical session, this questionnaire, the students were asked to express their anonymous opinion of the tool with the aim to analyze the contribution of the tool on the learning process of decoupling control applied on wind turbines. The assessment and evaluation carried out is based on [13], [33],[34], [35].

Questionnaire items are combined in four subscales: "Learning value", "Value added" and "Design usability and easy understanding of the tool". In the following, the purpose of each item is described:

- Learning value includes questions that try to reflect student's perceptions of how effectively is the software tool designed to learn about decoupling control concepts and its applicability in wind turbine processes.

- Value added tries to evaluate the use of the tool and the lab-scale wind turbine in the sense of theoretical lecture complement.

- Design usability and easy understanding of the tool focuses on student's perceptions of the ease and clarity to navigate through the graphical interface. 


\section{Results}

The questionnaire is summarized in Table 4. Learning value subscale encompasses the first three items. The next four items are related with Value added. The last three items evaluate the Design usability and easy understanding of the tool. In Table 5, the responses of the students are given. These responses were rated as strongly agree, agree, neutral, disagree or strongly disagree.

Figure 13 details the survey responses of 30 students. The percentage of strongly agree and agree answers was high compared to the rest. This indicates that the students emphasize the use of the tool to learn and consolidate new concepts of control engineering. Most of them found the graphical user interface userfriendly. Nevertheless, the interactivity level was penalized. The survey results have helped to consider new future enhancements of the tool, some of them are implemented in the downloadable version of wtControlGUI.

Table 4 Student questionnaire

\begin{tabular}{ll}
\hline Learning value \\
Q1 & $\begin{array}{l}\text { Did the tool enhance your ability to understand the theoretical material in a new } \\
\text { way? }\end{array}$ \\
Q2 & $\begin{array}{l}\text { Did the tool help you to visualize the new concepts of decoupling control in wind } \\
\text { turbines? } \\
\text { Do you think that you have gained as much information as you would from a lecture } \\
\text { explanation? }\end{array}$ \\
\hline Value added & $\begin{array}{l}\text { Did the tool help you to improve your theoretical knowledge of MIMO control } \\
\text { Q4 }\end{array}$ \\
Q5 & $\begin{array}{l}\text { Were you able to work through the experiences in a way that could not have been } \\
\text { possible by attending to a traditional lab? }\end{array}$ \\
Q6 & $\begin{array}{l}\text { Were you able to understand the possibility of application of different control } \\
\text { strategies over renewable energy systems, such as wind turbines? }\end{array}$ \\
Q7 & Was the level of interactivity in the tool adequate? \\
\hline Design usability and easy understanding of the tool \\
Q8 & $\begin{array}{l}\text { Was the wtcontrolGUI easy to understand and use? } \\
\text { Q9 }\end{array}$ \\
Did you think that the graphical user interface is user-friendly? \\
Were the ideas and concepts with the tool clearly presented and easy to follow?
\end{tabular}

Table 5 Student responses of the tool survey (Number of students $=30$ )

\begin{tabular}{lccccc}
\hline Group items & $\begin{array}{c}\text { Strongly } \\
\text { agree }\end{array}$ & Agree & Neutral & Disagree & $\begin{array}{c}\text { Strongly } \\
\text { disagree }\end{array}$ \\
\hline $\begin{array}{l}\text { Learning } \\
\text { value }\end{array}$ & $35 \%$ & $33 \%$ & $32 \%$ & $0 \%$ & $0 \%$ \\
\hline
\end{tabular}




\begin{tabular}{|c|c|c|c|c|c|}
\hline$(\mathrm{Q} 1, \mathrm{Q} 2, \mathrm{Q} 3)$ & & & & & \\
\hline $\begin{array}{l}\text { Value added } \\
\text { (Q4, Q5, Q6, } \\
\text { Q7) }\end{array}$ & $32 \%$ & $27 \%$ & $40 \%$ & $1 \%$ & $0 \%$ \\
\hline $\begin{array}{l}\text { Design } \\
\text { usability and } \\
\text { easy } \\
\text { understanding } \\
\text { of the tool } \\
\text { (Q8, Q9, } \\
\text { Q10) }\end{array}$ & $35 \%$ & $62 \%$ & $2 \%$ & $1 \%$ & $0 \%$ \\
\hline
\end{tabular}

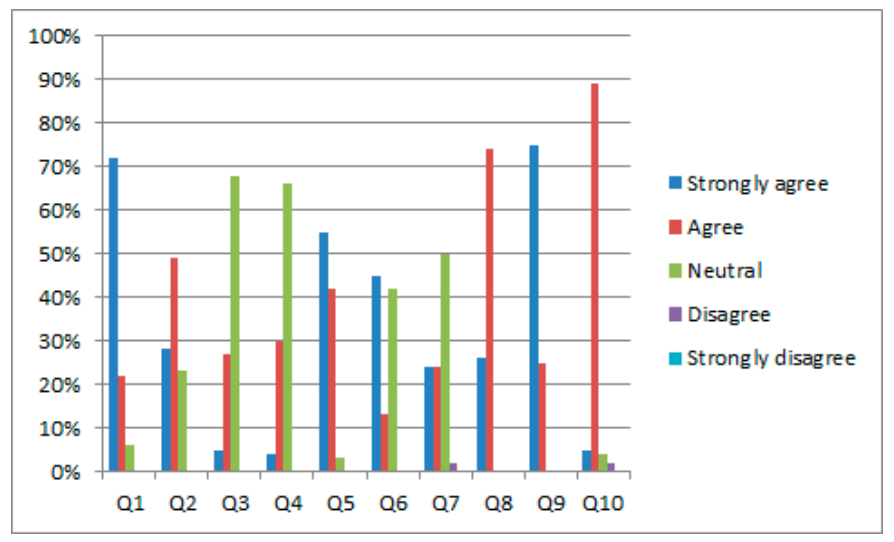

Figure 13 Student survey answers

\section{CONCLUSIONS AND FUTURE WORK}

This paper has presented and educational software tool specifically focused on decoupling control techniques applied on wind turbines. The developed tool provides different functionality modes, where the connection with a lab-scale system is possible. This makes it ideal for using in pedagogy, especially for control engineering practical laboratories.

Student feedback and assessment data indicate that the learning objectives were achieved. The student response was satisfactory, showing a high degree of interest for the use of the tool in understanding decoupling control concepts and the advantages of their application.

Future work will be mainly focused on adding new functionalities and interactivity to the tool. In this sense, in order to provide a better comparison between control strategies, a robustness analysis will be included. 


\section{ACKNOWLEDGMENT}

This work was supported by the Autonomous Government of Andalusia (Spain), under the Excellence

Project P10-TEP-6056. This support is gratefully acknowledged.

\section{REFERENCES}

[1] F. Wu, X. Zhang, S. Member, P. Ju, and M. J. H. Sterling, "Decentralized Nonlinear Control of Wind Turbine With Doubly Fed Induction Generator,” IEEE Trans. Power Syst., vol. 23, no. 2, pp. 613-621, 2008.

[2] H. Badihi, Y. Zhang, and H. Hong, "Wind Turbine Fault Diagnosis and Fault-Tolerant Torque Load Control Against Actuator Faults," IEEE Trans. Control Syst. Technol., vol. 23, no. 4, pp. 1351-1372, 2015.

[3] E. Assareh and M. Biglari, "A novel approach to capture the maximum power from variable speed wind turbines using PI controller, RBF neural network and GSA evolutionary algorithm," Renew. Sustain. Energy Rev., vol. 51, pp. 1023-1037, 2015.

[4] A. Jain, G. Schildbach, L. Fagiano, and M. Morari, "On the design and tuning of linear model predictive control for wind turbines," Renew. Energy, vol. 80, pp. 664-673, 2015.

[5] R. Rocha and L. S. M. Filho, "A multivariable H/sub $\infty /$ control for wind energy conversion system," in Proceedings of 2003 IEEE Conference on Control Applications, 2003. CCA 2003., 2003, vol. 19, pp. 206-211.

[6] R. M. Imran, D. M. Akbar Hussain, and Z. Chen, "LQG controller design for Pitch Regulated Variable Speed Wind Turbine," in IEEE International Energy Conference (ENERGYCON), 2014, pp. 101-105.

[7] G. Cao, K. M. Grigoriadis, and Y. D. Nyanteh, "LPV Control for the Full Region Operation of a Wind Turbine Integrated with Synchronous Generator,” Sci. World J., vol. 2015, 2015.

[8] L. Y. Pao and K. E. Johnson, "A tutorial on the dynamics and control of wind turbines and wind farms," in 2009 American Control Conference, 2009, pp. 2076-2089.

[9] F. Vázquez, F. Morilla, and S. Dormido, “An Iterative Method for Tuning Decentralized PID Controllers,” in 14th IFAC World Congress, 1999, pp. 491-496.

[10] J. Garrido, F. Vázquez, F. Morilla, and T. Hagglund, "Practical Advantages of Inverted Decoupling," Proc. Inst. Mech. Eng. Part I J. Syst. Control Eng., vol. 7, pp. 977-992, Jul. 2011.

[11] C. Jauch, J. Matevosyan, T. Ackermann, and S. Bolik, "International comparison of requirements for connection of wind turbines to power systems," Wind Energy, vol. 8, no. February 2004, pp. 295-306, 2005.

[12] D. Santos-Martin, J. Alonso-Martinez, J. Eloy-Garcia Carrasco, and S. Arnaltes, "Problem-Based Learning in Wind Energy Using Virtual and Real Setups," IEEE Trans. Educ., vol. 55, no. 1, pp. 126-134, 2012.

[13] J. Sánchez, S. Dormido, R. Pastor, and F. Morilla, “A Java/Matlab-based environment for remote control system laboratories: Illustrated with an inverted pendulum," IEEE Trans. Educ., vol. 47, no. 3, pp. 321-329, 2004.

[14] D. Cooper and D. Fina, "Training simulators enhance process control education," in Proceedings of the 1999 American Control Conference, 1999, vol. 2, no. June, pp. 997-1001. 
[16] MathWorks, "Real-Time Windows Target for use with Real-Time Workshop,” 1999.

[17] F. Bianchi, H. De Battista, and R. Mantz, Wind turbine control systems: principles, modelling and gain scheduling design. SpringerVerlag, 2006.

[18] A. R. Jha, Wind Turbine Technology. Taylor \& Francis, 2014, pp. 1-5.

[19] O. Anaya-Lara, N. Jenkins, J. Ekanayake, P. Cartwright, and M. Hughes, Wind Energy Generation: Modelling and Control. John Wiley \& Sons, 2009, p. 289.

[20] B. Boukhezzar and H. Siguerdidjane, "Nonlinear control of variable speed wind turbines for power regulation," in Proceedings of 2005 IEEE Conference on Control Applications, 2005. CCA 2005., 2005, no. 2, pp. 114-119.

[21] B. Boukhezzar, L. Lupu, H. Siguerdidjane, and M. Hand, "Multivariable control strategy for variable speed, variable pitch wind turbines," Renew. Energy, vol. 32, no. 8, pp. 1273-1287, Jul. 2007.

[22] M. García-Sanz and E. Torres, “Control y Experimentación del Aerogenerador Síncrono de Velocidad Variable TWT1650," Rev. Iberoam. automática e informática Ind., vol. 1, pp. 53-62, 2004.

[23] L. Dodson, K. Busawon, and M. Jovanovic, "Estimation of the power coefficient in a wind conversion system," in 44th IEEE Conference on Decision and Control, and the European Control Conference, 2005, pp. 3450-3455.

[24] G. Van Der Veen, "Identification of Wind Energy Systems,” Delft Technical University (Holland), 2013.

[25] S. Fragoso, J. Garrido, F. Vázquez, and F. Morilla, "Comparative analysis of decoupling control methodologies and Hœ multivariable robust control for VS-VP wind turbines," in 6th International Renewable Energy Congress (IREC), 2015.

[26] F. Morilla, J. Garrido, and F. Vázquez, "Multivariable Control by Decoupling,” Rev. Iberoam. Automática e Informática Ind. RIAI, vol. 10, no. 1, pp. 3-17, Jan. 2013.

[27] M. G. Ortega and F. R. Rubio, "Systematic design of weighting matrices for the Hœ mixed sensitivity problem," J. Process Control, vol. 14, no. 1, pp. 89-98, Feb. 2004.

[28] M. G. Ortega, F. Castaño, M. Vargas, and F. R. Rubio, "Multivariable robust control of a rotary dryer: Analysis and design," Control Eng. Pract., vol. 15, pp. 487-500, 2007.

[29] M. L. Ruz, F. Morilla, and F. Vázquez, "Teaching control with first order time delay model and PI controllers," in 8th IFAC Symposium on Advances in Control Education, 2009, vol. 8, no. 2, pp. 31-36.

[30] Á. Ruiz, J. E. Jiménez, J. Sánchez, and S. Dormido, "Design of event-based PI-P controllers using interactive tools,” Control Eng. Pract., vol. 32, pp. 183-202, 2014.

[31] S. M. Barakati, "Modeling and Controller Design of a Wind Energy Conversion System Including a Matrix Converter," University of Waterloo, Ontario (Canada), 2008.

[32] J. G. Balchen, M. Handlykken, and A. Tyss, "The need for better laboratory experiments in control engineering education," in 8th IFAC World Congress. Control Science and Technology for Progess of Society, 1981, pp. 3363-3368.

[33] R. Dormido, H. Vargas, N. Duro, J. Sánchez, S. Dormido-Canto, G. Farias, F. Esquembre, and S. Dormido, "Development of a webbased control laboratory for automation technicians: The three-tank system," IEEE Trans. Educ., vol. 51, no. 1, pp. 35-44, 2008.

[34] C. M. Ionescu, E. Fabregas, S. M. Cristescu, S. Dormido, and R. De Keyser, "A remote laboratory as an innovative educational tool for practicing control engineering concepts," IEEE Trans. Educ., vol. 56, no. 4, pp. 436-442, 2013.

[35] D. C. Morales, J. E. Jiménez-hornero, F. Vázquez, and F. Morilla, "Educational Tool for Optimal Controller Tuning Using Evolutionary Strategies," IEEE Trans. Educ., vol. 55, no. 1, pp. 48-57, 2012. 
